\title{
Barbicidal overdose
}

\author{
Asim Nayeem • Samer Elkhodair • \\ Thiagarajan Jaiganesh
}

Received: 21 August 2010 /Accepted: 11 October 2010 /Published online: 6 November 2010

(C) The Author(s) 2010. This article is published with open access at Springerlink.com

\begin{abstract}
Acute severe methemoglobinaemia is an uncommon but life-threatening condition caused by a variety of oxidizing agents commonly used in both health care and industrial settings. Thus, recognition is important as it is readily treatable. The oxygen transport is compromised as a result of abnormal levels of oxidized haemoglobin, and this leads to skin discolouration and a variety of symptoms. Diagnostic confusion occurs as the oxygen saturations (SpO2) on the pulse oximeter are unreliable (Sharma V, Haber A. Acquired methaemoglobinaemia: a case report of benzocaine-induced methaemoglobinaemia and a review of the literature. Clin Pul Med. 2002;9(1):53-8). A case of severe methaemoglobinaemia due to self poisoning with barbicide is presented with a brief discussion of the pathophysiology and an overview of the treatment. A barbicidal overdose has never been reported before.
\end{abstract}

Keywords Barbicide $\cdot$ Methemoglobinaemia $\cdot$ Methylene blue Isopropyl alcohol $\cdot$ Benzalkonium chloride

\section{Case report}

A 53-year-old female was blue lighted into our emergency department resuscitation room by ambulance crew as she

The patient gave her written consent for publication of the photographs in this article.

\footnotetext{
A. Nayeem $\cdot$ S. Elkhodair $\cdot$ T. Jaiganesh $(\bowtie)$

St Georges Hospital,

Blackshaw road,

Tooting SW17 0QT London, UK

e-mail: jaiganesh@doctors.org.uk

A. Nayeem

e-mail: tigum@hotmail.com

S. Elkhodair

e-mail: samer.elkhodair@stgeorges.nhs.uk
}

appeared extremely cyanotic from face to feet. She complained of nausea, vomiting and difficulty in breathing. Her most striking feature was a bluish hue of her face (Fig. 1) including her lips and forearms. She looked as if she had fallen onto blue ink and had some residual staining. However, closer examination revealed that this discolouration was present throughout, including her nails (Fig. 2). Oxygen therapy had made no difference to her appearance. She appeared confused and was unable to give any coherent history.

She was tachycardic (130/min) and tachypnoeic (30/min), and had a $\mathrm{SpO} 2$ of $90 \%$ on 151 oxygen; blood pressure was $100 / 50 \mathrm{mmHg}$. Chest examination revealed few crackles in both mid zones, and a possible chemical/ apsiration pneumonitis was suspected. She had a history of deliberate self harm. She had no allergies and worked as a beautician by profession.

Arterial blood gas (ABG) analysis on oxygen showed pH 7.41 (7.35-7.45), pCO2 $3.44 \mathrm{kPa}$ (4.7-6), pO2 $31.6 \mathrm{kPa}(11-13$ on room air), lactate $11.0(<2)$, base excess $-7.2 \mathrm{mmol} / \mathrm{l}(-2-+2)$ and $\mathrm{HCO} 319.4 \mathrm{mmol} / \mathrm{l}(24-31)$. The patient continued to receive high-flow oxygen and intravenous access was gained, and bloods tests, including paracetomol and salicylate levels, and a urine toxicology for the usual drugs of abuse were requested. These subsequently turned out to be negative. She was treated with intravenous crystalloids for compensated metabolic acidosis and treated with antibiotics to cover for aspiration pneumonia. A differential diagnosis for high anion gap metabolic acidosis was worked out using the common mnemonic (MUD PILES-Methanol, Uremia, Diabetic ketoacidosis, Paraldehyde, Iron, Lactic acid, Ethanol and ethylene glycol, and Salicylates, respectively) as the anion gap was 21 (3-11). Despite her treatment, there was no sign of improvement. The initial chest $\mathrm{x}$-ray was normal.

A diagnosis of methaemoglobinemia was suspected in our patient as she demonstrated (1) central cyanosis 


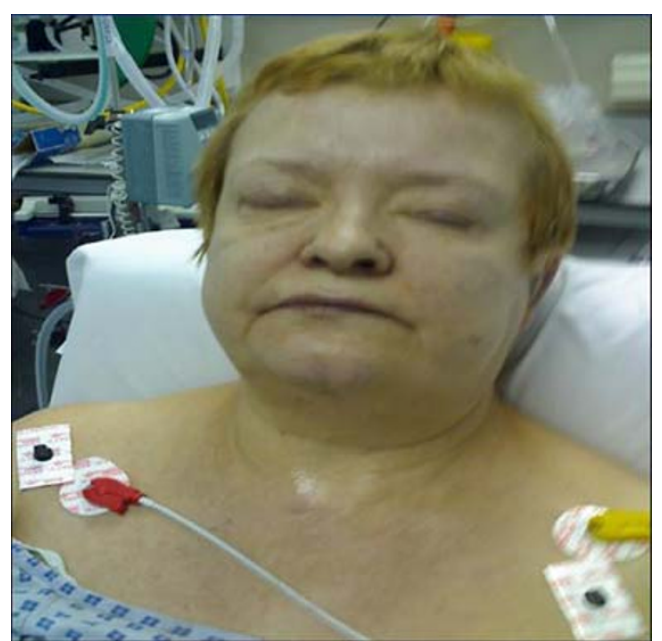

Fig. 1 Facial cyanosis

unresponsive to oxygen therapy with no previous history of congenital cardiac disease or causes for pulmonary hypertension; (2) decreased oxygen saturation on the pulse oximeter with a near normal pO2; (3) difference in the arterial blood gas (95\%) and the pulse oximeter (90\%) oxygen saturation measurements; and (4) she was a beautician with a history of self harm (beauty products when ingested can result in methaemoglobinaemia). An urgently requested methaemoglobin $(\mathrm{MetHb})$ level showed a raised MetHb level (50.3\%), which confirmed the diagnosis. She was subsequently treated with a slow intravenous dose of methylene blue $(2 \mathrm{mg} / \mathrm{kg})$. Clinical improvement was marked within $20 \mathrm{~min}$. Her tachycardia and tachypnoea began to settle, and she was now able to communicate.

Her repeat $\mathrm{ABG}, 30$ min post treatment, showed $\mathrm{pH}$ 7.37, pCO2 4.12, pO2 11.6, lactate 6.4, base excess -6.8 , cHCO3 19.2 and MetHb 2.9\%. She acknowledged the fact that she had consumed alcohol but refused to answer the

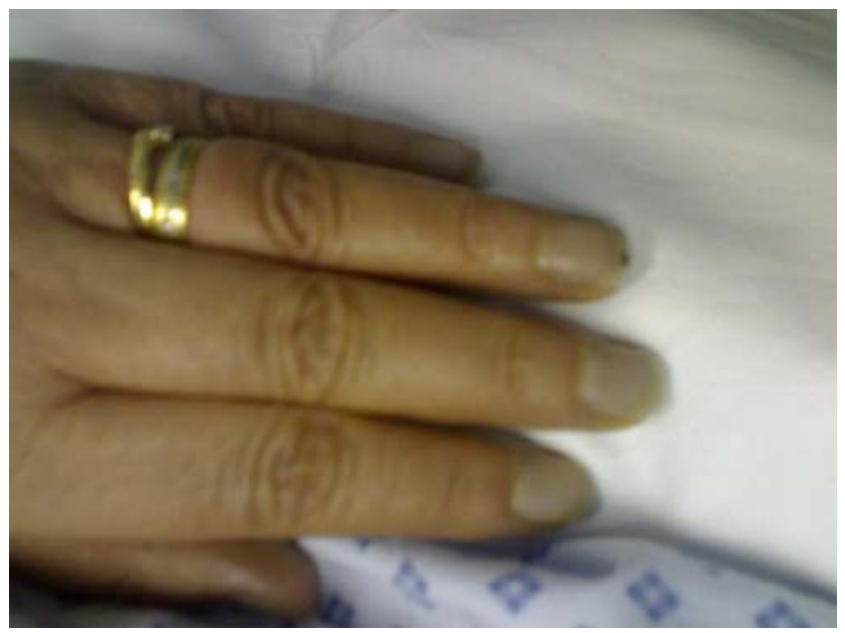

Fig. 2 Peripheral cyanosis deliberate self-harm questions. She was observed in a resuscitation room with regular $\mathrm{ABG}$ monitoring through an arterial line and then transferred to the intensive care unit where her recovery was complicated by the development of ARDS. ARDS was confirmed on a CT scan and was thought to be vasogenic or neurogenic in origin rather than aspiration or infective. She gradually improved and was eventually discharged from the hospital about 10 days later. Psychiatric counseling revealed that she had ingested a barbicide, and outpatient follow-up including chest clinic was arranged prior to discharge from the hospital. She was reviewed in the chest clinic for up to 3 months and had made an excellent recovery and did not have any ongoing respiratory symptoms, and hence was discharged from follow-up.

\section{Discussion}

Barbicide is a translucent blue disinfectant solution (Fig. 3) that is used not only in beauty salons to disinfect items such as combs and scissors, but also in hospitals as it has viricidal, bactericidal and fungicidal properties [1]. The three important ingredients are isopropyl alcohol, sodium nitrite and dimethyl benzyl ammonium chloride, which result in high anion gap acidosis, methaemoglobinaemia and normal anion gap acidosis, respectively, when ingested. Signs and symptoms usually start within $30 \mathrm{~min}$ after ingestion.

Fig. 3 Barbicide

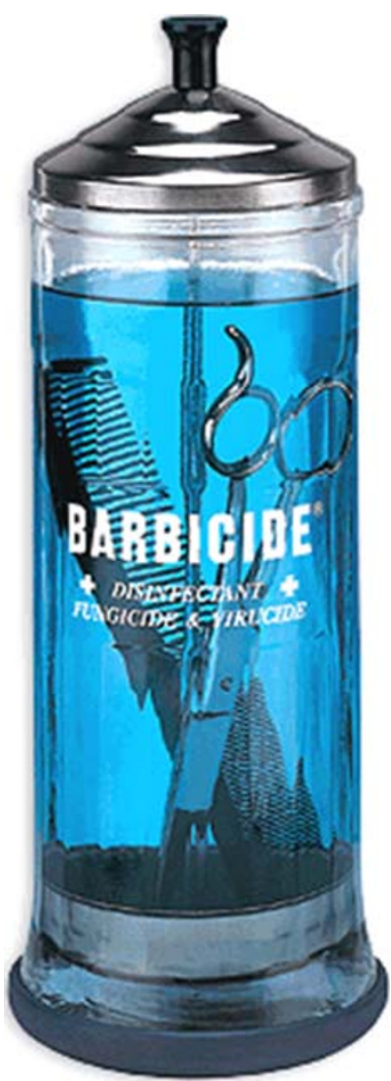


Methaemoglobinaemia should be a part of the differential diagnosis spectrum in a blue, breathless, acidotic patient unresponsive to oxygen therapy as it is a potentially fatal, yet readily treatable condition. A clue to the diagnosis is bluish discolouration of skin, and the blood has a chocolate brown colour [2]. The diagnosis can be confirmed by requesting MetHb levels, which are mostly available in modern blood gas analysers. The sample should be analysed very soon after being drawn, as the MetHb level in the sample will decrease with time.

Haemoglobin $(\mathrm{Hb})$ can accept and transport oxygen only when the iron atom is in its ferrous form $\left(\mathrm{Fe}^{2+}\right)$. When haemoglobin loses an electron and becomes oxidized, it is converted to the ferric state $\left(\mathrm{Fe}^{3+}\right)$ or MetHb. MetHb lacks the ability to transport oxygen. The major pathway that handles $95 \%$ of MetHb under physiological conditions is the Embden-Meyerhoff pathway in which there is an enzymatic reduction of MetHB to $\mathrm{Hb}$ by the enzyme NADH (nicotinamide adenine dinucleotide) MetHb reductase [3]. Because red blood cells are continuously exposed to various oxidant stresses, blood normally contains approximately $2 \% \mathrm{MetHb}$ levels [4]. Methemoglobinemia may be passed down through families (inherited) or commonly acquired as a result of exposure to certain drugs, chemicals or foods (acquired). The most commonly implicated agents include dapsone, local (topical) anaesthetic agents, aniline dyes and nitrates [5]. Anaemic patients and G6PD-deficient patients are more susceptible to methaemoglobinaemia.

Differing MetHb levels in blood produce various symptoms:

- $10-20 \%$, usually asymptomatic despite cyanosis

- $20-30 \%$, headache, dyspnoea and anxiety

- $30-50 \%$, tachycardia, dizziness, palpitaions and fatigue

- $50-70 \%$, acidosis, confusion, coma and seizures

- $>70 \%$, fatal.

Use of methylene blue can be life-saving and is considered the treatment of choice. Methylene blue (MB), given intravenously in a dose of 1 to $2 \mathrm{mg} / \mathrm{kg}$ over $5 \mathrm{~min}$, usually provides a rapid improvement in the patient's condition; the dose may be repeated in $1 \mathrm{~h}$ if the level of $\mathrm{MetHb}$ remains high, but retreatment is frequently not necessary. Contraindications to methylene blue are G6PD deficiency and renal failure [6]. Supplemental antioxidants such as ascorbic acid (vitamin $\mathrm{C}$ ), $\mathrm{N}$-acetylcysteine and tocopherol (vitamin E) have been used as adjuvants or alternatives to methylene blue with no confirmed benefit [7]. Severely affected patients may benefit from adjunctive treatment with hyperbaric oxygen and/or exchange transfusion, although evidence of their efficacy is only anecdotal $[8,9]$. The differential diagnosis is sulfhaemoglobinemia, which refers to the inclusion of a sulfur molecule into the heme moiety. This does not respond to methylene blue treatment [10].

Isopropyl alcohol (IPA) is a colourless liquid with bitter taste commonly used in deicers and as a sterilising agent in window cleaners and many disinfectants. It is rapidly absorbed and reaches peak plasma levels within 30 $60 \mathrm{~min}$. IPA is metabolised by the enzyme alcohol dehydrogenase to acetone. Alcohols compete with IPA for this enzyme, and the average half life of IPA can be prolonged from $4 \mathrm{~h}$ to $16 \mathrm{~h}$ with co-ingestion of alcohol. Early clinical features include nausea, vomiting, abdominal pain, tachycardia, headache and dizziness. Severe poisoning can lead to haematemesis, melena, bradycardia, hypotension, dysrhythmias, hypo- or hyperglycemia, rhabdomyolysis, renal failure, respiratory depression, convulsions and coma. Clinical suspicion is raised by the sweetsmelling, fruity acetone on the breath. However, raised anion gap metabolic acidosis on the blood gas with raised osmolar gap secondary to high serum acetone levels is strongly suggestive of IPA poisoning [11]. Treatment is usually supportive, and haemodialysis is rarely needed.

Dimethyl benzyl ammonium chloride (benzalkonium chloride) is often used as a disinfectant. Clinical features of ingestion include vomiting, diarrhoea and foaming at the mouth if the concentration is less than $10 \%$. Higher concentrations can lead to corrosive damage to the oropharynx and the oesophagus, and should be managed accordingly. Haematemesis and circulatory collapse can also occur. Vomiting in the presence of foaming can lead to aspiration, and the foaming can be minimised with dimeticone.

\section{Conclusion}

Acute methaemoglobinemia is usually associated with high mortality, and an early aggressive treatment with intravenous methylene blue is potentially life-saving. A high level of suspicion with a relevant history of exposure or ingestion to a toxin or drug is often the key to the diagnosis.

Conflicts of Interest All authors declare that they have no conflicts of interest to declare.

Open Access This article is distributed under the terms of the Creative Commons Attribution Noncommercial License which permits any noncommercial use, distribution, and reproduction in any medium, provided the original author(s) and source are credited.

\section{References}

1. Barbicide Material Safety Data Sheet. http://www.kings-research. com $/$ pdf $/ \mathrm{msds} /$ Barbicide_MSDS.pdf

2. Caudil L, Walbridge J, Kuhn G (1990) Methaemoglobinaemia as a cause of coma. Ann Emer Med 19:677-679 
3. Edwards RJ, Ujma J (1995) Extreme methaemoglobinaemia secondary to recreational use of amyl nitrite. J Acc Emer Med 12:138-142

4. Yawata Y, Ding L, Tanishima K, Tomoda A (1992) New variant of cytochrome $b_{5}$ reductase deficiency (b5Rkurashiki) in red cells, platelets, lymphocytes, and cultured fibroblasts with congenital methemoglobinemia, mental and neurological retardation, and skeletal anomalies. Am J Hematol 40:299-305

5. Kane G, Hoehn S, Behrenbeck T, Mulvagh SL (2007) Benzocaine-induced methaemoglobinaemia based on the Mayo Clinic experience from 28,478 transoesophageal echocardiograms. Arch Intern Med 167(18):1977-1982

6. Mokhlesi B (2003) Adult toxicology in critical care. Part II: specific poisonings. Chest 123:897-952

7. Bradberry SM (2003) Occupational methaemoglobinaemia. Mechanisms of production, features, diagnosis and manage- ment including the use of methylene blue. Toxicol Rev 22 (1):13-27

8. Lindenmann J, Matzi V, Kaufmann P, Krisper P, Maier A, Porubsky C, Smolle-Juettner FM (2006) Hyperbaric oxygenation in the treatment of life-threatening isobutyl nitrite-induced Methemoglobinemia-A case report. Inhalation Toxicology 18 (13): 1047-1049

9. Pritchett MA, Celestin N, Tilluckdharry N, Hendra K, Lee P (2006) Successful treatment of refractory methemoglobinemia with red blood cell exchange transfusion. Chest 130:294S-a

10. Demedts P, Wauters A, Watelle M, Neels H (1997) Pitfalls in discriminating sulfhemoglobin from methemoglobin [letter]. Clin Chem 43:1098-1099

11. Zaman F, Pervez A, Abreo K (2002) Isopropyl alcohol intoxication: a diagnostic challenge. Am J Kidney Dis 40:E12 